International Journal of

BioScience and Applications

\title{
Analysis of Recognition of Nutrition Labeling in Korean: Report Based on 2019 Korea National Health and Nutrition Examination Survey Data
}

\author{
Hae-Ryoung Park \\ Department of General Education, Kwangju Women's University, Republic of Korea
}

\begin{abstract}
${ }^{1}$
Background/Objectives: The purpose of this study was to promote the use of nutrition labeling along with the need for more systematic education on easier nutrition labeling so that the public can easily access it. Nutrition labeling recognition was a method that helps people of all ages to choose healthier foods to improve their nutritional intake, so we intend to analyze them based on KNHANES VII-1 data. Methods/Statistical analysis: The data were analyzed the data using IBM SPSS 21.0 program. Frequency analysis and chi-square test method was conducted. The significance level was set at $p<.01$. Findings: As a result of whether or not nutrition labeling is recognized, the number of women who answered 'yes' was high at $70.0 \%(2,759$ people) higher than average (68.4\%). Looking at the general matters of the survey subjects, '30-39' was $92.3 \%$, '40-49' $91.5 \%$, and '50-59' $81.0 \%$ in that order. Regarding nutrition label recognition, 30-39 showed a very high recognition rate. On the other hand, the recognition rate of nutrition labeling was $19.9 \%$ for those over 80 years old. It was thought that education on nutrition labeling recognition will be necessary from the age of 60 or older. Regardless of the level of learning, it was found that the nutrition labeling recognition was high. By income level, 'low' 42.3\%, ' Low \& middle' 61.5\%, ' Middle ' 69.9\%, 'Middle \& high ' 73.8\%, and 'High' 82.6\%, indicating that the higher the income, the higher the nutrition labeling recognition. Improvements/Applications: The younger and the higher the educational level, the more fully they knew about nutrition labeling. Based on this study, a more systematic nutrition awareness education was needed, and the use of nutrition labeling was to be activated.
\end{abstract}

\section{Index Terms}

Nutrient, Recognition of Nutrition Labeling, Korea National Health and Nutrition Examination Survey, Healthy life, Nutrition intake

\footnotetext{
Corresponding author: Hae-Ryoung Park

hrpark@kwu.ac.kr

- Manuscript received April 15, 2021.

- Revised May 14, 2021 ; Accepted June 1, 2021.

- Date of publication June 30, 2021

(C) The Academic Society of Convergence Science Inc.

2619-8363 $\odot 2021$ IJBSA. Personal use is permitted, but republication/redistribution requires IJBSA permission.
} 


\section{INTRODUCTION}

A varied diet was important to staying healthy, and an unhealthy diet was the leading cause of death and disability worldwide [1]. As part of a comprehensive policy response to promote healthier diets and prevent non-communicable diseases (NCDs), WHO recommends that governments implement front-ofpacket (FOP) nutrition labels [2,3]. The nutrition labeling system or food nutrition information labeling system was a statutory labeling system for processed foods or imported products, established in the 'Food Sanitation Act' and the 'Food Labeling and Advertising Act' and enforced in 1994. The purpose was to contribute to the promotion of public health by increasing consumers' utilization of food, promoting the quality improvement of food nutrition, and providing correct information about food.

The nutrition labeling system provides information on nutrition to consumers, such as the type and content of nutrients contained in food, calories when consumed, and the ratio of each nutritional component to the recommended daily intake. It was also a system to help consumers make rational food choices based on the nutritional value of food [4].

Complement detailed nutrition labeling on the back of the packaging by providing at-a-glance information on nutritional quality. There was growing evidence that these labels can help consumers understand nutritional quality, encourage healthier food choices and purchases, and promote industry-specific reorganization. If you properly understand and consume the information on accurate nutrition labeling, you can solved the calorie imbalance and establish a healthy eating culture with a balanced diet. Therefore, this study intended to analyzed basic data on whether koreans are aware of nutrition labeling based on the seventh Korea National Health and Nutrition Examination Survey (KNHANES VIII-1). In addition, based on these data, it was intended to provide basic data for future use of nutrition labeling and research on nutrients of interest.

\section{Research Method}

The 7th National Health and Nutrition Examination Survey (KNHANES VII-1) used in this study was a statistical survey conducted by the Korea Disease Control and Prevention Agency based on the Statistical Act. The data downloaded for this study did not include information that can confirm the identity of the study subject, and the data used was used only for this study and was not used for any other purpose. The Korea Disease Control and Prevention Agency provides only de-identified data so that individuals cannot be estimated in accordance with the Personal Information Protection Act and the Statistical Act.

\section{A. Research design}

This study was a secondary analysis using raw data from the seventh Korea National Health and Nutrition Examination Survey (KNHANES VII -1) conducted by the Korea Disease Control and Prevention Agency in 2019 to understand the actual situation of nutrition labeling recognition. A total of 7,184 subjects (male 3,279 and female 4378) were surveyed, and 8,107of them were analyzed excluding missing values.

\section{B. General Characteristics}

For general characteristics in this study, data on gender, age, education, and house income among health survey data from the seventh Korea National Health and Nutrition Examination Survey were used. Education level was classified into ' $<$ middle school', 'middle school', 'high school', and 'university graduate or higher'. Age was based on age, '20-29', '30-39, '40-49', '50-59', '60-69', '70-79', and '80 years old or older classified as'. As for house income, household income was divided into 'low', 'lowermiddle', 'middle', 'middle-high', and 'high' based on income quartiles.

Frequency analysis was performed to find out the general characteristics of the subjects. In order to find the perceived health status, nutrition labeling recognition, use of nutrition labeling, and nutrition education of the subject, it was analyzed by the frequency analysis method.

In order to examine the differences in nutrition 
labeling recognition by general characteristics, crossanalysis (chi-square test) used in the case of nonparametric method in categorical data was conducted to examine the differences between groups.

\section{Analysis Method}

The data were analyze the data using IBM SPSS 21.0 program. Frequency Analysis and chi-square test method was conducted. The significance level was set at $\mathrm{p}<.01$.

\section{ReSUltS}

\section{A. General Characteristics}

The results regarding the general characteristics of the study subjects are as follows. The total number of participants was 8107 , and each item was the result of excluding missing values. Table 1 shows the results of the general characteristics of the subjects were expressed through frequency analysis.

Table 1. General characteristics

\begin{tabular}{|c|c|c|c|}
\hline Characteristics & Categories & $\mathrm{N}$ & $\%$ \\
\hline \multirow[t]{3}{*}{ gender } & $\operatorname{man}$ & 3729 & 46.0 \\
\hline & women & 4378 & 54.0 \\
\hline & Total & 8107 & 100.0 \\
\hline \multirow[t]{8}{*}{ age } & $20-29$ & 749 & 9.2 \\
\hline & $30-39$ & 985 & 12.1 \\
\hline & $40-49$ & 1182 & 14.6 \\
\hline & $50-59$ & 1245 & 15.4 \\
\hline & $60-69$ & 1186 & 14.6 \\
\hline & $70-79$ & 846 & 10.4 \\
\hline & $>80$ & 349 & 4.3 \\
\hline & Total & 6542 & 80.7 \\
\hline \multirow[t]{5}{*}{ Education } & $<$ Middle school & 2273 & 28.0 \\
\hline & Middle school & 755 & 9.3 \\
\hline & High school & 2011 & 24.8 \\
\hline & $\geq$ University & 2293 & 28.3 \\
\hline & Total & 7332 & 90.4 \\
\hline \multirow[t]{6}{*}{ House income } & Low & 1076 & 13.3 \\
\hline & Low \& middle & 1492 & 18.4 \\
\hline & Middle & 1716 & 21.2 \\
\hline & Middle \& high & 1936 & 23.9 \\
\hline & High & 1847 & 22.8 \\
\hline & Total & 8067 & 99.5 \\
\hline
\end{tabular}

For the overall analysis of Perceived Health Status, Nutrition Labeling Recognition, Nutrition Education, and Use of Nutrition Labeling, it was organized through frequency analysis as shown in in Table 2.

Table 2. Respondent's perceived health status, nutrition labeling recognition, nutrition education, and use of nutrition labeling

\begin{tabular}{|c|c|c|c|}
\hline Characteristics & Categories & $\mathrm{N}$ & $\%$ \\
\hline \multirow{7}{*}{$\begin{array}{c}\text { Perceived } \\
\text { Health Status }\end{array}$} & Very good & 663 & 8.2 \\
\hline & Good & 2195 & 27.1 \\
\hline & Normal & 3418 & 42.2 \\
\hline & $\mathrm{Bad}$ & 874 & 10.8 \\
\hline & Very bad & 202 & 2.5 \\
\hline & Unknown & 354 & 4.4 \\
\hline & Total & 7706 & 95.1 \\
\hline \multirow{5}{*}{$\begin{array}{c}\text { Nutrition } \\
\text { Labeling } \\
\text { Recognition }\end{array}$} & Yes & 4889 & 60.3 \\
\hline & No & 1840 & 22.7 \\
\hline & Unmatched & 418 & 5.2 \\
\hline & Unknown & 1 & 0.0 \\
\hline & Total & 7148 & 88.2 \\
\hline \multirow{5}{*}{$\begin{array}{l}\text { Nutrition } \\
\text { Education }\end{array}$} & Yes & 756 & 9.3 \\
\hline & No & 5973 & 73.7 \\
\hline & Unmatched & 418 & 5.2 \\
\hline & Unknown & 1 & 0.0 \\
\hline & Total & 7148 & 88.2 \\
\hline \multirow{5}{*}{$\begin{array}{c}\text { Use of } \\
\text { Nutrition } \\
\text { Labeling }\end{array}$} & Yes & 1745 & 21.5 \\
\hline & No & 3144 & 38.8 \\
\hline & Unmatched & 2258 & 27.9 \\
\hline & Unknown & 1 & 0.0 \\
\hline & Total & 7148 & 88.2 \\
\hline
\end{tabular}

Among the nutrition labeling, interest was high in the order of calories, sugar, sodium, trans fat, and protein. It was organized through frequency analysis as shown in in Table 3.

Table 3. Respondent's nutrients of interest in nutrition labeling

\begin{tabular}{|c|c|r|r|}
\hline Characteristics & Categories & \multicolumn{1}{|c|}{$\mathrm{N}$} & \multicolumn{1}{|c|}{$\%$} \\
\hline Nutrients of & Calori & 620 & 7.6 \\
\cline { 2 - 4 } & Carbohadrate & 95 & 1.2 \\
\cline { 2 - 4 } & Sugar & 243 & 3.0 \\
\cline { 2 - 4 } & Protein & 141 & 1.7 \\
\cline { 2 - 4 } & Fat & 89 & 1.1 \\
\cline { 2 - 4 } & Saturated fat & 45 & 0.6 \\
\cline { 2 - 4 } & Trans Fat & 156 & 1.9 \\
\cline { 2 - 4 } & Cholesterol & 110 & 1.4 \\
\cline { 2 - 4 } & Sodium & 226 & 2.8 \\
\cline { 2 - 4 } & Etc & 20 & 0.2 \\
\cline { 2 - 4 } & Unmatched & 5402 & 66.6 \\
\cline { 2 - 4 } & Unknown & 1 & 0.0 \\
\cline { 2 - 4 } & Total & 7148 & 88.2 \\
\hline
\end{tabular}




\section{B. Nutrition Labeling Recognition}

As a result of whether or not nutrition labeling was recognized, the number of women who answered 'yes' was high at $70.0 \%$ (2,759 people) higher than average $(68.4 \%)$ as shown in in Table 4.

Table 4. Nutrition label recognition according to gender

\begin{tabular}{|l|l|c|c|c|c|}
\hline Characteristics & Categories & \multicolumn{4}{|c|}{ Nutrition Labeling Recognition } \\
\cline { 3 - 6 } & & \multicolumn{2}{|c|}{ Yes } & \multicolumn{2}{|c|}{ No } \\
\cline { 3 - 6 } & & $\mathrm{N}$ & $\%$ & $\mathrm{~N}$ & $\%$ \\
\hline \multirow{3}{*}{ Gender } & man & 2130 & 66.4 & 862 & 26.9 \\
\cline { 2 - 6 } & women & 2759 & 70.0 & 978 & 24.8 \\
\hline Total & 4889 & 68.4 & 1840 & 25.7 \\
\hline$\chi 2(\mathrm{p})$ & \multicolumn{4}{|c|}{$13.754(.003) * * *$} \\
\hline $\mathrm{p}^{*} 0.05, \mathrm{p}^{* *}<.01, \mathrm{p}^{* * *<.001}$
\end{tabular}

Looking at the general matters of the survey subjects, '30-39' was $92.3 \%$, '40-49' $91.5 \%$, and '50-59' $81.0 \%$ in that order shown in in Table 5.

Table 5. Nutrition Labeling Recognition

\begin{tabular}{|c|c|c|c|c|c|}
\hline \multirow[t]{3}{*}{ Characteristics } & \multirow[t]{3}{*}{ Categories } & \multicolumn{4}{|c|}{ Nutrition Labeling Recognition } \\
\hline & & \multicolumn{2}{|c|}{ Yes } & \multicolumn{2}{|c|}{ No } \\
\hline & & $\mathrm{N}$ & $\%$ & $\mathrm{~N}$ & $\%$ \\
\hline \multirow[t]{7}{*}{ Age } & $20-29$ & 574 & 92.7 & 45 & 7.3 \\
\hline & 30-39 & 789 & 92.3 & 66 & 7.7 \\
\hline & $40-49$ & 948 & 91.5 & 88 & 8.5 \\
\hline & $50-59$ & 859 & 81.0 & 201 & 18.9 \\
\hline & $60-69$ & 662 & 63.3 & 384 & 36.7 \\
\hline & $70-79$ & 273 & 34.7 & 513 & 65.3 \\
\hline & $>80$ & 64 & 19.9 & 258 & 80.1 \\
\hline \multicolumn{2}{|c|}{ Total } & 4169 & 72.8 & 1555 & 27.2 \\
\hline \multicolumn{2}{|l|}{$\chi 2(\mathrm{p})$} & \multicolumn{4}{|c|}{$1591.761(.000) * * *$} \\
\hline
\end{tabular}

By education level, $37.0 \%$ of ' $<$ Middle school', $69.9 \%$ of 'Middle school', $80.5 \%$ of 'High school', and $91.7 \%$ of ' $\geq$ University' were ' High school', and '> University ' or higher. Regardless of the level of learning, it was found that the nutrition labeling recognition was high as shown in in Table 6 .

Table 6. Nutrition labeling recognition according to education level

\begin{tabular}{|l|c|c|c|c|c|}
\hline \multirow{2}{*}{ Characteristics } & Categories & \multicolumn{3}{|c|}{ Nutrition Labeling Recognition } \\
\cline { 3 - 6 } & & \multicolumn{2}{|c|}{ Yes } & \multicolumn{2}{|c|}{ No } \\
\cline { 3 - 6 } & $\mathrm{N}$ & $\%$ & $\mathrm{~N}$ & $\%$ \\
\hline Education & $\begin{array}{c}<\text { Middle } \\
\text { school }\end{array}$ & 776 & 37.0 & 929 & 44.2 \\
\hline
\end{tabular}

\begin{tabular}{|l|c|c|c|c|c|}
\hline \multirow{7}{*}{} & $\begin{array}{c}\text { Middle } \\
\text { school }\end{array}$ & 449 & 69.9 & 193 & 30.1 \\
\cline { 2 - 6 } & High school & 1380 & 80.5 & 335 & 19.5 \\
\cline { 2 - 6 } & $\geq$ University & 1831 & 91.7 & 165 & 8.3 \\
\hline Total & 4436 & 68.7 & 1622 & 25.1 \\
\hline$\chi 2(\mathrm{p})$ & \multicolumn{3}{|c|}{$1876.129(.000)^{* * *}$} \\
\hline $\mathrm{p}^{*<.05, \mathrm{p}^{* *}<.01, \mathrm{p}^{* * *}<.001}$
\end{tabular}

By income level, 'low' $42.3 \%$, ' Low \& middle' $61.5 \%$, ' Middle ' $69.9 \%$, 'Middle \& high ' $73.8 \%$, and 'High' $82.6 \%$, indicating that the higher the income, the higher the nutrition labeling recognition as shown in in Table 7.

Table 7. Nutrition labeling recognition according to house income level

\begin{tabular}{|c|c|c|c|c|c|}
\hline \multirow[t]{3}{*}{ Characteristics } & \multirow[t]{3}{*}{ Categories } & \multicolumn{4}{|c|}{ Nutrition Labeling Recognition } \\
\hline & & \multicolumn{2}{|c|}{ Yes } & \multicolumn{2}{|c|}{ No } \\
\hline & & $\mathrm{N}$ & $\%$ & $\mathrm{~N}$ & $\%$ \\
\hline \multirow[t]{5}{*}{ House income } & Low & 404 & 42.3 & 534 & 56.9 \\
\hline & $\begin{array}{l}\text { Low \& } \\
\text { middle }\end{array}$ & 823 & 61.5 & 438 & 32.7 \\
\hline & Middle & 1050 & 69.9 & 327 & 21.8 \\
\hline & $\begin{array}{c}\text { Middle \& } \\
\text { high }\end{array}$ & 1267 & 73.8 & 319 & 18.6 \\
\hline & High & 1328 & 82.6 & 205 & 12.7 \\
\hline \multicolumn{2}{|l|}{ Total } & 4872 & 68.4 & 1832 & 25.7 \\
\hline \multicolumn{2}{|l|}{$\chi 2(p)$} & \multicolumn{4}{|c|}{$767.052(<.001) * * *$} \\
\hline
\end{tabular}

\section{Conclusion AND Discussion}

$70.0 \%$ of women answered 'yes' to the question of nutrition labeling recognition showed higher interest than men.

Most of the students $(93.1 \%)$ were aware of the nutrition label of processed foods, but the number of students who actually check the nutrition label when purchasing processed food was lower (45.4\%), and especially the male students were significantly lower than the female students [5].

Regarding nutrition labeling recognition, the age of $30 \sim 39$ showed a very high recognition rate. However, the recognition rate of nutrition labeling was very low among those over 80 years old at $19.9 \%$. It was thought that education on nutrition label recognition will be necessary from the age of 60 or older.

Nutrition labeling awareness was a way to help people of all ages improve their nutritional intake by making healthier food choices. However, in the elderly, cognition of nutritional labeling did not affect nutritional intake. In particular, the elderly over the age of 70 who was vulnerable to health and 
have various diseases were vulnerable to nutrition label recognition. It was hoped that nutrition labeling education would be continued for these vulnerable subjects in the future, and this study intended to provide basic data to help those who are vulnerable to nutrition education and nutrition labeling. Nutrition label awareness was a way to help people of all ages improve their nutritional intake by making healthier food choices. However, the recognition rate of nutrition labeling was lower than the average when the educational level was lower than middle school. The higher the educational level, the more positive the responses to nutrition label recognition. It was hoped that research will continue to increase the recognition rate of nutrition labeling even if the educational level was low.

The perception of nutrition labeling of processed foods was $38.7 \%$ in a study of middle school students and $65.4 \%$ in a study of high school students $[6,7]$.

Participants in the study made their purchases by looking at nutritional labels on packaged products. Participants checked nutrition labels for convenience foods, cereals, snack foods, bread and bakery products, and oils. Label identification was low for sugar and honey products, eggs, fish, fruits and vegetables, and meat. After the participants looked at the label, the products they bought were much healthier [8].

As the aging society enters an aging society, the elderly was becoming the main target market for the food industry, so more research on the use of nutrition labeling should be conducted with this age group in mind. Therefore, more systematic education on easier nutrition labeling was needed so that the elderly and people with low educational attainment can easily access it.

\section{REFERENCES (APA STYLE)}

[1] Afshin A, Sur PJ, Fay KA, et al. Health effects of dietary risks in 195 countries, 1990-2017: a systematic analysis for the global burden of disease study 2017. Lancet. 2019;393:1958-72.

[2] Stuckler D, McKee M, Ebrahim S, et al. Manufacturing epidemics: the role of global producers in increased consumption of unhealthy commodities including processed foods, alcohol, and tobacco. PLoS Med. 2012;9:e1001235

[3] Hall KD, Ayuketah A, Brychta R, et al. Ultraprocessed diets cause excess calorie intake and weight gain: an inpatient randomized controlled trial of AD libitum food intake. Cell Metab. 2019;30:6777.

[4] Son HS, Chang YK. Understanding nutrition labeling and standard of labeling of food. Food
Science and Industry. 1997;30: 69-76.

[5] Dan Bi Lee, Myung-Hee Kim, Mi-Kyeong Choi. Recognition of Nutritional Labeling and Intake Status of Processed Foods and Snacks among High School Students in Incheon. $J$ Korean Diet Assoc. 2021;27(1):15-25.

[6] Lee JI, Kim JH, Jung IK. Perception and usage of food \& nutrition labels in junior high school students. Korean J Community Living Sci. 2008;19(4):559-568. [7] Park SH, Kim MJ, Chang KJ. High school students' perception and confirmation on food labeling in purchase of processed food in Gyeonggi area - focused on gender and recognition on food labeling. J Living Sci Res. 2016; 42:71-84.

[8] Cliona Ni Mhurchu, Helen Eyles, Yannan Jiang, Tony Blakely. Do nutrition labels influence healthier food choices? Analysis of label viewing behaviour and subsequent food purchases in a labelling intervention trial. Appetite. 2018;121(1):360-65. 